\title{
The COVID TIDE Approach: A Protocol for Safe Tracheostomy Practice in COVID Patients
}

\author{
Deepa Shivnani $^{1}$ (D) Eshwara V. Raman ${ }^{1} \cdot$ Dnyanesh Amle $^{2}$
}

Received: 21 October 2020/Accepted: 4 January 2021 / Published online: 18 January 2021

(C) Association of Otolaryngologists of India 2021

\begin{abstract}
We all are aware of COVID 19 pandemic. As the numbers are increasing, the critical care demand is also increasing. Tracheostomy is one of the commonest procedures which has been performed on COVID positive ventilated patients. It is important to understand and follow the utmost safe practices for the patient and the health care workers for such aerosol generating procedures. The aim of this study is to identify the lacunae in tracheostomy practices during this COVID times and suggest a systematic approach for the safe practices. An online questionnaire survey-based study was performed in September 2020. The target population was practicing otolaryngologists of India with various years of experience. The aim of the study was to evaluate the lacunae in tracheostomy safe practices and to create a systematic approach for the safety of health care workers. Data compilation and analysis was done by using Microsoft Excel. A systematic COVID TIDE tracheostomy safe practices approach was designed after reviewing various tracheostomy guidelines and recommendations. Total 114 otolaryngologists responded with a complete survey report. $72.2 \%$ responders were not up to date with their knowledge of tracheostomy safe practices. $79.8 \%$ were not performing this procedure in a negative pressure room. $15.8 \%$ were not aware of the personal protective equipment
\end{abstract}

Supplementary Information The online version contains supplementary material available at https://doi.org/10.1007/ s12070-021-02370-w.

Deepa Shivnani

deepa.shivnani14@gmail.com

1 Department of Otorhinolaryngology, Head and Neck Surgery, Children's Airway and Swallowing Center, Manipal Hospital, Bengaluru, Karnataka, India

2 Department of Biochemistry, AIIMS, Nagpur, India level they are using. Only $56.1 \%$ survey responders were holding the ventilation before tracheal incision. Overall, 94.7\% responders were keen to know about the safe approach of tracheostomy in COVID positive patients. Tracheostomy is an aerosol generating procedure, lacunae in the knowledge can cause major risk to health care professionals. Finally, in such crises, consideration should be taken for simulation exercises, dedicated airway teams and a systematic COVID TIDE approach to improve the safety of the staff and patients.

Keywords Airway · COVID · Safe practice · Tracheostomy $\cdot$ Viral filters

\section{Introduction}

The novel coronavirus disease 2019 (COVID 19) is impacting hospital care worldwide. The major morbidity associated with COVID 19 is acute respiratory distress syndrome (ARDS) which in severe condition requires ventilatory support [1]. In prolonged ventilation and weaning, tracheostomy holds an important element of care. Otolaryngologists play a major role in performing tracheostomy during this pandemic. Tracheostomy as an aerosol generating procedure, is associated with increased risk of viral infection to the otolaryngologists [2]. Various guidelines and recommendations on safe practice for tracheostomy procedure are available since lockdown but the implementation of those amongst the otolaryngologists is not studied so far. Therefore, we decided to conduct a nationwide survey amongst the ear, nose and throat specialists to analyse the lacunae in tracheostomy practices during this COVID times and suggest a systematic approach for the safe practices. 
Image 1 A systematic COVID TIDE approach

\section{THE COVID TIDE APPROACH}

\begin{tabular}{|c|c|c|}
\hline & COVERING GUIDELINES & $\begin{array}{l}\text { - PPE level } 3 \text { with PAPR } \\
\text { - FFP 3/N99 or FFP 2/N95 with surgical } \\
\text { mask } \\
\text { - Head Cover/ Eye Goggle/ Face Shield/ } \\
\text { Gown/ Gloves/ Shoe Cover }\end{array}$ \\
\hline & OPERATION THEATRE PLANNING & $\begin{array}{l}\text { - Dedicated COVID theatre } \\
\text { - } \text { - Legative pressure room } \\
\text { - Syringe attached with the } \\
\text { tracheostomy tube } \\
\text { - Availability of viral filters for } \\
\text { endotracheal tube \& for tracheostomy } \\
\text { tube }\end{array}$ \\
\hline & VENTILATOR PRECAUTIONS & $\begin{array}{l}\text { Suction of endotracheal tube/ Sub } \\
\text { glottic port } \\
\text { Hold ventilation before incision over } \\
\text { trachea until the intraluminal } \\
\text { confirmation of tracheostomy tube } \\
\text { with inflated cuff }\end{array}$ \\
\hline & INCISION PRECAUTIONS & $\begin{array}{l}\text { - Muscle relaxants } \\
\text { - Stay sutures for pediatric cases before } \\
\text { giving the incision } \\
\text { - Hold the ventilation as described }\end{array}$ \\
\hline & DOFFING PROTOCOL & $\begin{array}{l}\text { - Buddy check before doffing } \\
\text { - Look for tear or blood stains over the } \\
\text { gown } \\
\text { - Dedicated doffing zone }\end{array}$ \\
\hline & TUBE CHANGE PLANNING & $\begin{array}{l}\text { Between 14-21 days or until patient is } \\
\text { negative for COVD } 19 \text { testing }\end{array}$ \\
\hline & IN LINE CLOSED SUCTION & $\begin{array}{l}\text { Always use in line closed suction } \\
\text { catheter system }\end{array}$ \\
\hline & DECANNULATION & $\begin{array}{l}\text { - Local expertise and protocols } \\
\text { - Full level protection to prevent aerosol } \\
\text { contamination }\end{array}$ \\
\hline 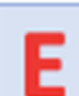 & EXPERT AIRWAY TEAM & $\begin{array}{l}\text { - Dedicated and experienced COVID } \\
\text { airway team }\end{array}$ \\
\hline
\end{tabular}

\section{Methods}

It was an online questionnaire survey-based study done in the month of September 2020. The target population was practicing otolaryngologists of India with various years of experience. The aim of the study was to evaluate the lacunae in tracheostomy safe practice and to create a systematic approach for safety of the health care workers. By using google form engine, an anonymous survey questionnaire was designed to study the practice patterns of ENT surgeons for tracheostomy in the COVID-19 situation. The questionnaire (Images 6, 7, 8, 9, 10, 11) was in English language and contained 16 multiple choice questions which were mandatory and 2 optional questions regarding the specific topic they would wish to learn and their email contact details for further communication. It was then sent to the randomly selected otolaryngologists practising in India via email, text message, various social 
Image 2 Ventilation

precautions during table shift

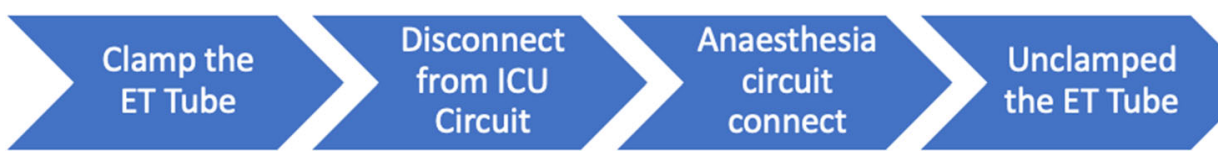

HOLD VENTILATION - Tracheal cartilage exposure(before entering the airway) until the tracheostomy tube cuff is inflated and capnography confirms intraluminal location
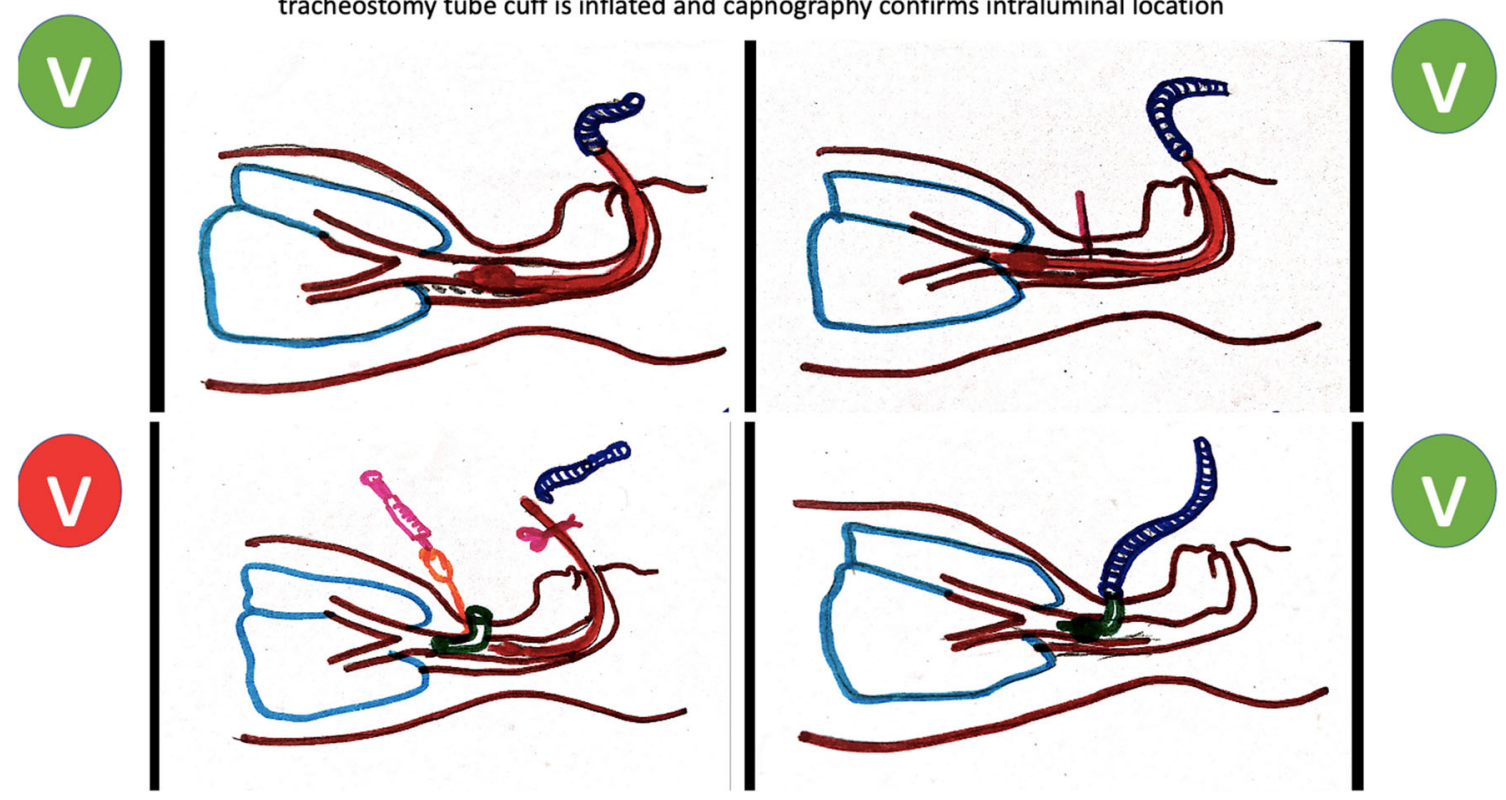

Image 3 Ventilation hold before tracheal incision till the tube position is confirmed by capnography

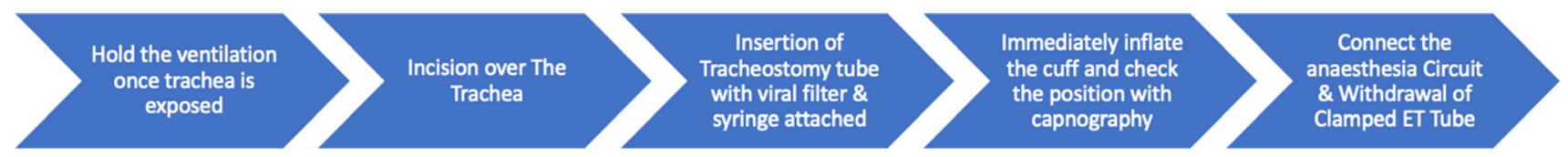

Image 4 Steps for ventilation pause

Image 5 Steps for post tracheostomy care
- T- TUBE CHANGE- Day $7^{\text {th }}, 4-6$ weeks interval, when blocked

- R- REGULAR CLEANING-Tube/stoma/equipment

- A- AIRWAY PROTECTION-Gauze, HME, Trach bibs

- C- COMPLICATION AWARENESS-Block, granulation, bleeding, pain

- H- HOME KIT REQUIREMENT-Must have!

- E- EMERGENCY SITUATIONS-Call for help!

- O- ORAL HYGIENE-Brushing twice daily.

- S- STOMA/SKIN CARE-Regular dressing and cleaning.

- T- TIES CARE-Change when required.

- O- OUTER \& INNER TUBE CLEANING-As required.

- M- MUCOUS PROBLEMS-Appropriate tubing, till tip, $80-120 \mathrm{mmHg}$ pressure.

- Y- YOUR CHILD'S SAFETY-Look for breathing, listen trach sound, feel the air blast. 
Image 6 Questionnaire part 1

\section{Tracheostomy - Safe practices during COVID 19 Era}

Tracheostomy is one of the most commonly performed airway surgery and COVID status has changed certain steps for this procedure for safe practices during this pandemic. Please take this 45 second questionnare to know about critical steps of Tracheostomy safe practices.

* Required

Have you performed tracheostomy in last 6 months ?(Since March 2020) *

$\bigcirc$ Yes No

If yes, have you checked the COVID status of your patients? *

$\bigcirc$ Yes

No

Have you performed tracheostomy on COVID POSITIVE patients? *

$\bigcirc$ Yes

$\bigcirc$ No

I don't know

media platforms i.e. WhatsApp and Facebook groups of otolaryngologists with an online link of the survey. Online access to the questionnaire was available from 1st September 2020 to 15 th September 2020. Data compilation and analysis were done using Microsoft Excel. A systematic COVID TIDE tracheostomy safe practice approach was designed after reviewing various tracheostomy recommendations and guidelines published by international societies of otolaryngology, which can be practiced in India. Since the COVID situation and recommendations are evolving, few of the recommendations may change later.

\section{Results}

A total of 114 ENT doctors responded with a complete survey report.

$81.6 \%$ responders said that they have performed the tracheostomy in the last 6 months. $69.3 \%$ checked the COVID status of the patient before performing the procedure. Only $25.4 \%$ responded that they have performed this procedure on COVID positive cases and for $14.9 \%$ responders, the status was unknown.

While asking about their up to date knowledge regarding tracheostomy safe practices in COVID Positive patients, surprisingly $72.2 \%$ responded with no and I don't know responses, only $29.8 \%$ responders said yes. In response to 
Image 7 Questionnaire part 2

Do you feel that your knowledge is up to date regarding tracheostomy safe practices in COVID Positive patients ? *
$\bigcirc$ Yes
No
I don't know

Operation theatre

Emergency room

Do you perform your Tracheostomy procedure(s) in negative pressure $\quad 1$ point room?*

$\bigcirc$ Yes

No

the question regarding the place of the tracheostomy procedure $68.4 \%$ said operation theatres, $23.7 \%$ and $7.9 \%$ said ICU and emergency room respectively.

While asking about the tracheostomy procedure in the negative pressure room, $79.8 \%$ responders said no, only $20.2 \%$ responded yes. $61.4 \%$ were using the level 3 PPE for this procedure and $15.8 \%$ were not aware of what PPE level they were using. Inquiring about the mask protection $55.3 \%$ responded for $\mathrm{N} 95$ and surgical masks in combination, 36\% were using only N95 masks, 5.3\% were using only surgical masks and surprisingly only $3.5 \%$ were using PAPR.

Regarding viral filters usage on endotracheal (ET) tubes before connecting to the ventilator, only $32.5 \%$ responders said yes, $44.7 \%$ said no and $22.8 \%$ said they did not know about this step. Similarly, the usage of heat moisture exchanger (HME) filters on tracheostomy were practiced only by $21.1 \%$ responders.

While asking about the usage of neuromuscular blockade agents for complete paralysis of the patient, $50 \%$ said yes, $30.7 \%$ responded no and $19.3 \%$ said they did not know.

Inquiring about holding the ventilation before giving the tracheal incision only $56.1 \%$ responder said yes. Regarding clamping of ET tube before withdrawal, surprisingly only $25.4 \%$ were following this step. The use of non-fenestrated cuffed tubes were practised only by $66.7 \%$ responders. We asked if they would like to know more about safe practices during tracheostomy procedure and post-operative care, $94.7 \%$ responders said yes. 
Image 8 Questionnaire part 3

Which type of mask protection do you use? *

0 points

PAPR

N95

Surgical Mask

N95 \& Surgical Mask

I'm not sure

Do you use viral filters on ET tube before connecting to the ventilator ?* 1 point

Yes

No

I don't know

Does your anaesthetist use neuromuscular blockade agents for complete $\quad 1$ point paralysis of the patient ?*

Yes

No

I don't know

About 33 individual comments were entered for specific topics or steps that they would like to learn about this procedure. A few extracts from individual responses are stated like, "percutaneous tracheostomy in COVID era, post op care in tracheostomy patients in COVID era, about viral filters in tracheostomy, role of anaesthetist in different steps of tracheostomy, tracheostomy till tube insertion and special COVID precautions during tracheostomy". 74 responders out of 114 shared their mail address for further communication in this regard.

\section{Discussion}

Though the various guidelines and protocols are available since June 2020 [3-7] the survey results are surprising as $72 \%$ survey responders were not confident about their knowledge. No surveys have been conducted solely to address this issue though the various tracheostomy guidelines have come up during these crises. Our study data was collected from 114 ENT surgeons from India; however, it has served the purpose of the survey. After reviewing various guidelines and recommendations, a systematic COVID TIDE approach was formed as described in Image 1. 
Image 9 Questionnaire part 4

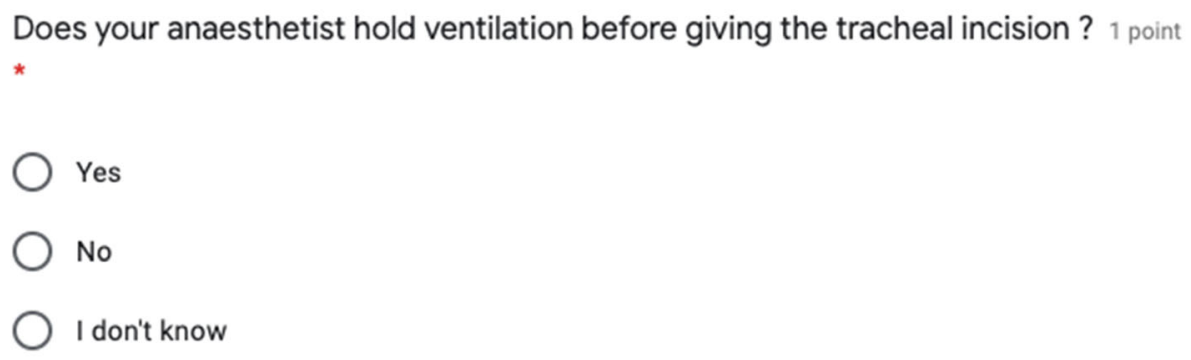

Does your anaesthetist hold ventilation while inserting the tracheostomy 1 point tube ?*

Y Yes

$\bigcirc$ No

I don't know

Does your anaesthetist clamp the ET tube before withdrawing ? * 1 point

Yes
No
I don't know

\section{Covering Guidelines}

Ideal recommendations for tracheostomy procedure are full PPE (with FFP3/FFP2 mask, fluid repellent full covered gown, head cover, shoe cover, gloves, face shield with eye protection) [8] but despite wearing $\mathrm{N} 95$ respirators during SARS pandemic some health care workers acquired the disease so the use of powered air purifying respirators(PAPR) was recommended by some clinicians [5, 8-10]. In spite of such recommendations, in our series PAPR user number was only $3.5 \%$.

\section{Operation Theatre Planning}

There should be dedicated COVID theatre. The ideal recommendations are negative pressure theatre or isolation room [5]. Though in our survey we found that $78.9 \%$ surgeons were not performing this procedure in a negative pressure room. Consider a normal theatre with closed doors if the negative pressure room is not available.

Limited staff should be permitted inside the theatre. Availability of viral filters for endotracheal tube \& for tracheostomy tube is recommended [10] but surprisingly in our survey only $32.5 \%$ responders were aware of filter usage.

\section{Ventilator Precautions}

Suction of endotracheal tube/ Sub glottic port is recommended prior to the shifting of the patient to operation theatre. A close communication between anaesthesia and surgical team is necessary. Ventilation precaution should be taken during the table shift of the patient too. (Image 2).

The ventilation pause is a very critical step and should be done just before giving the incision over the trachea. The ventilation can be resumed once the tube position is confirmed with EtCO2 and the cuff is inflated. (Image 3). 
Image 10 Questionnaire part 5

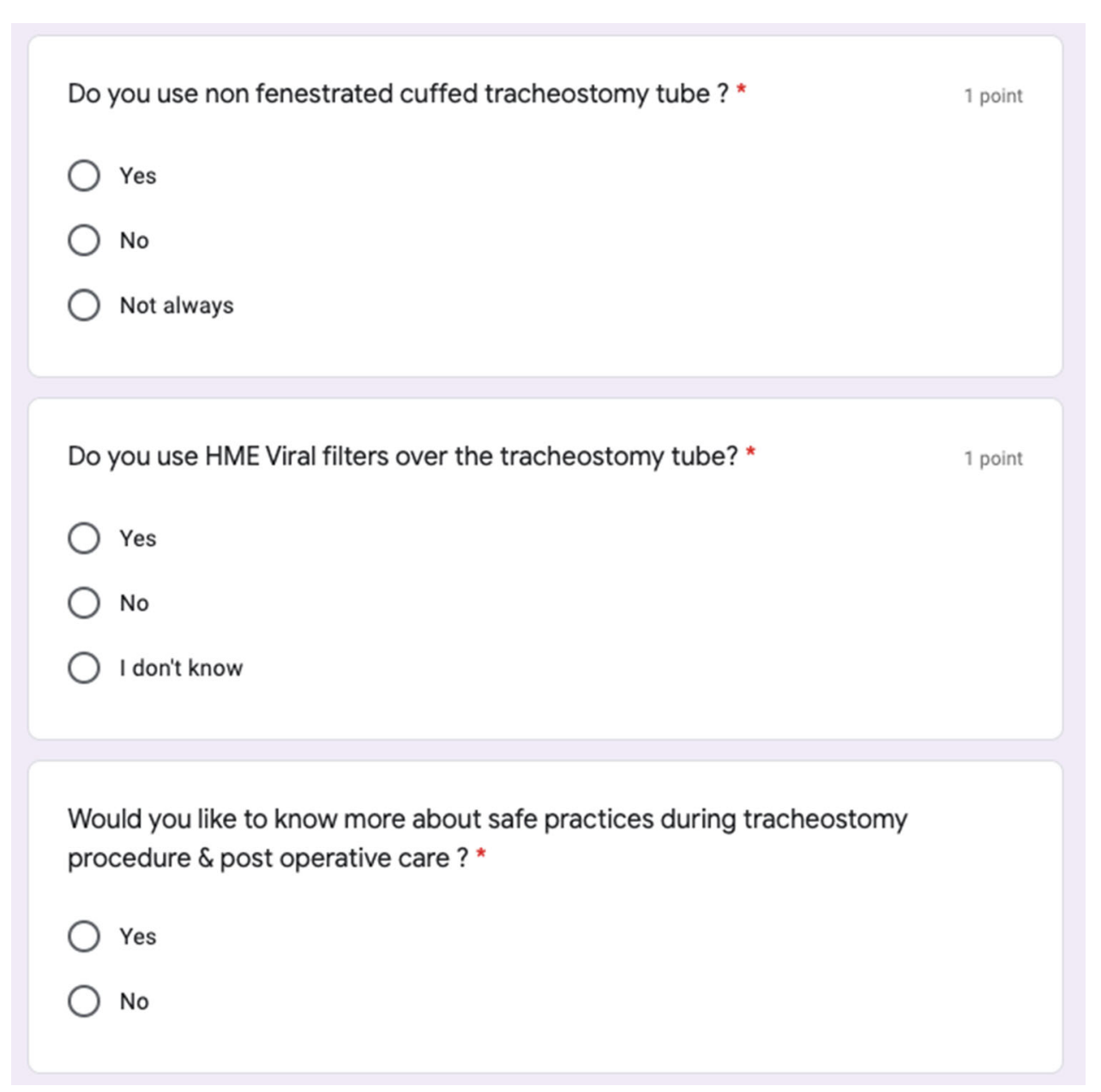

Further the disinfection of the ventilators should be followed as per the guidelines of infection control department of the hospital.

\section{Incision Precautions}

During open tracheostomy procedure, neuromuscular blockade should be given to reduce the cough reflex and movements, which was followed only by $50 \%$ responders according to our survey report. Stay sutures should be placed for paediatric cases before giving the incision. Consider clamping of ET tube before creating the tracheal window. Ensure to create a sufficient size tracheal window for easy insertion of the tube [9]. To prevent air leak and aerosol, the cuffed non fenestrated tracheostomy tube is preferred. An empty syringe should be attached to the tracheostomy tube. Immediately inflate the cuff once the position of the tube is confirmed and then reattach the circuit [5, 7] but again this was followed by $56.1 \%$ responders only. Hold the ventilation as described previously and shown in Image 4 as well.

\section{Doffing Protocol}

Appropriate donning and doffing of PPE is the crucial step for prevention of contamination. Look for the tear or blood stains over the gown. There should be a dedicated doffing zone to prevent cross contamination. Strict adherence to the proper protocol and buddy check can avoid the risk of self-contamination while doffing $[8,10]$.

\section{Tube Change Care}

The usual tube care is not replaced in COVID cases too. (Image 5) The limited number of experienced staff should be involved in post tracheostomy care to avoid aerosol contamination. Regarding first tube change, majority of recommendations are in the favor of between 14 and 21 days or until patient is negative for COVID 19 testing $[3,11,12]$.

While performing tracheostomy care, cuff deflation and tracheostomy dressing should be avoided unless necessary to minimise aerosol generation. Tracheostomy care should be performed with the enhanced PPE with utilisation of 
Image 11 Questionnaire part 6

Do you use HME Viral filters over the tracheostomy tube? *

1 point
$\bigcirc$ Yes
No
I don't know

Would you like to know more about safe practices during tracheostomy

procedure \& post operative care ? *

$\bigcirc$ Yes

No

Please share specific step/topics that you would like to learn more about

Your answer

\section{(20)}

Please provide your email address for further communication.

Your answer

closed in line suction, HME filters and inflated cuff system. The frequency of tube change should be minimised to 2-3 months interval unless clinical emergency [13]. The inner cannula of the tube can be changed every $72 \mathrm{~h}$ [14] (Images 6, 7, 8, 9, 10, 11).

\section{In Line Closed Suction}

Always use in line closed suction catheter system regardless of mechanical ventilation requirements [13].

\section{Decannulation}

Local expertise and protocols should be followed. Droplet precautions are the minimal requirement to be followed while decannulating the patient to prevent aerosol contamination [15].

\section{Expert Airway Team}

A dedicated and experienced COVID airway team should be formed who can perform such procedures effectively with minimal risk to health care workers and the patient. Standardized COVID 19 tracheostomy simulation training might improve the health care professionals safety as well as the confidence in performing such procedures $[15,16]$.

\section{Conclusion}

The number of COVID positive patients are increasing day by day. The critically ill patients requiring ventilation support is the major burden to the hospital and the health care professionals. To facilitate the recovery time, tracheostomy is needed. With our study we concluded that in 
spite of various guidelines and available recommendations, the survey responders were still not confident in safe practices for tracheostomy procedure. To overcome this, we have created an easy to remember COVID TIDE approach in tracheostomy safe practice. After following COVID TIDE approach, our tertiary care centre with high volume COVID positive patient load performed this procedure efficiently and the risk of transmission is not found so far. This systematic approach is easy to follow and reproducible.

Acknowledgement We sincerely thank all the survey participants who has given their valuable time to recognize the current problem.

\section{Compliance with Ethical Standards}

Conflict of interest All authors declare the following: Payment info: We declare that we have not received any financial support from any organisation for this work submission. Financial relationships: We declare that we do not have any financial relationships with any organisation who is interested in this work. Other relationships: We declare that there are no other relationships that could influenced the work we have published.

\section{References}

1. Šifrer R, Urbančič J, Piazza C, van Weert S, García-Purriños F, Benedik J et al (2020) Emergent tracheostomy during the pandemic of COVID-19: Slovenian national recommendations. Eur Arch Otorhinolaryngol. https://doi.org/10.1007/s00405-02006318-8

2. Tran K, Cimon K, Severn M, Pessoa-Silva CL, Conly J (2012) Aerosol generating procedures and risk of transmission of acute respiratory infections to healthcare workers: a systematic review. PLoS ONE 7(4):e35797. https://doi.org/10.1371/journal.pone. 0035797

3. Pandian V, Morris LL, Brodsky MB, Lynch J, Walsh B, Rushton $\mathrm{C}$ et al (2020) Critical care guidance for tracheostomy care during the COVID-19 pandemic: a global, multidisciplinary approach. Am J Crit Care Off Publ Am Assoc Crit Care Nurses 29:e1-e12

4. Radhakrishnan S, Perumbally HA, Surya S, Ponneth MS (2020) Guidelines for surgical tracheostomy and tracheostomy tube change during the COVID-19 pandemic: a review article. Indian J Otolaryngol Head Neck Surg Off Publ Assoc Otolaryngol India 72(3):398-401

5. Takhar A, Walker A, Tricklebank S, Wyncoll D, Hart N, Jacob T et al (2020) Recommendation of a practical guideline for safe tracheostomy during the COVID-19 pandemic. Eur Arch Oto-
Rhino-Laryngol Off J Eur Fed Oto-Rhino-Laryngol Soc EUFOS Affil Ger Soc Oto-Rhino-Laryngol Head Neck Surg 277(8): 2173-2184

6. Rovira A, Dawson D, Walker A, Tornari C, Dinham A, Foden N et al (2020) Tracheostomy care and decannulation during the COVID-19 pandemic, A multidisciplinary clinical practice guideline. Eur Arch Otorhinolaryngol. https://doi.org/10.1007/ s00405-020-06126-0

7. Heyd CP, Desiato VM, Nguyen SA, O'Rourke AK, Clemmens CS, Awad MI et al (2020) Tracheostomy protocols during COVID-19 pandemic. Head Neck 42(6):1297-1302

8. David AP, Russell MD, El-Sayed IH, Russell MS (2020) Tracheostomy guidelines developed at a large academic medical center during the COVID-19 pandemic. Head Neck 42(6): 1291-1296

9. Wax RS, Christian MD (2020) Practical recommendations for critical care and anesthesiology teams caring for novel coronavirus (2019-nCoV) patients. Can J Anaesth J Can Anesth 67(5):568-576

10. Dharmarajan H, Snyderman CH (2020) Tracheostomy time-out: New safety tool in the setting of COVID-19. Head Neck 42(7): $1397-1402$

11. Shiba T, Ghazizadeh S, Chhetri D, St John M, Long J (2020) Tracheostomy considerations during the COVID-19 pandemic. OTO Open 4(2):2473974X20922528

12. Mattioli F, Fermi M, Ghirelli M, Molteni G, Sgarbi N, Bertellini E et al (2020) Tracheostomy in the COVID-19 pandemic. Eur Arch Oto-Rhino-Laryngol Off $\mathrm{J}$ Eur Fed Oto-Rhino-Laryngol Soc EUFOS Affil Ger Soc Oto-Rhino-Laryngol Head Neck Surg 277(7):2133-2135

13. Lamb CR, Desai NR, Angel L, Chaddha U, Sachdeva A, Sethi S et al (2020) Use of tracheostomy during the COVID-19 pandemic: American College of Chest Physicians/American Association for Bronchology and Interventional Pulmonology/ Association of Interventional Pulmonology Program Directors Expert Panel Report. Chest 158(4):1499-1514

14. Prabhakaran K, Malcom R, Choi J, Chudner A, Moscatello A, Panzica P et al (2020) Open tracheostomy for COVID-19-positive patients: A method to minimize aerosolization and reduce risk of exposure. J Trauma Acute Care Surg 89(2):265-271

15. Jacob T, Walker A, Mantelakis A, Gibbins N, Keane O (2020) A framework for open tracheostomy in COVID-19 patients. Clin Otolaryngol Off J ENT-UK Off J Neth Soc Oto-Rhino-Laryngol Cervico-Facial Surg 45(4):649-651

16. LoSavio PS, Eggerstedt M, Tajudeen BA, Papagiannopoulos P, Revenaugh PC, Batra PS et al (2020) Rapid implementation of COVID-19 tracheostomy simulation training to increase surgeon safety and confidence. Am J Otolaryngol 41(5):102574

Publisher's Note Springer Nature remains neutral with regard to jurisdictional claims in published maps and institutional affiliations. 